\title{
FAKTOR YANG MEMPENGARUHI UMKM UNTUK MENGADOPSI E-COMMERCE
}

\author{
Angelita Nauli Panggabean - 2301950881 - LB21
}

E-Business Strategy and Implementation

\begin{abstract}
Abstrak
Perkembangan teknologi yang semakin pesat, telah membuat penggunaan internet dan juga aktivitas perdagangan elektonik atau e-commerce semakin meningkat. Dengan begitu, ecommerce sangat berpotensial bagi para pelaku bisnis, termasuk UMKM. Tujuan karya tulis ini adalah untuk mengidentifikasi faktor-faktor apa saja yang menpengaruhi adopsi e-commerce bagi UMKM. Desain karya tulis ini menggunakan metode tinjauan Pustaka dimana penulis mencari dan mempelajari jurnal-jurnal, baik internasional maupun nasional yang didapatkan dari berbagai sumber melalui internet. Dari jurnal-jurnal tersebut dapat disimpulkan bahwa faktor pendorong adopsi e-commerce adalah dipengaruhi oleh faktor teknologi, perusahaan, dan lingkungan itu sendiri.
\end{abstract}

Kata Kunci: Adopsi E-commerce, UMKM

\section{Pendahuluan}

Perkembangan teknologi telah menuntut perusahaan untuk dapat bertahan dan mampu bersaing di tengah persaingan pasar yang ketat. Salah satu langkah yang dapat dilakukan perusahaan adalah dengan mengadopsi teknologi dalam proses bisnisnya (Saroso et al., 2019). Jumlah masyarakat Indonesia yang menggunakan internet pun semakin meningkat karena kemajuan teknologi dan juga aktivitas perdagangan elektronik atau e-commerce yang semakin berkembang (Ramdansyah \& Taufik, 2017). Penggunaan internet tidak hanya menjadi media jejaring, tetapi juga sebagai media bertransaksi bagi konsumen (Ramdansyah \& Taufik, 2017). Internet mempengaruhi cara orang berkomunikasi satu sama lain, memperoleh informasi, dan juga melakukan belanja online. Adopsi teknologi memungkinkan dapat memberikan keunggulan kompetitif bagi UMKM di era ekonomi baru, terutama dalam memasarkan produknya. Model bisnis yang akan mendominasi adalah perdagangan elektronik atau e-commerce. E-commerce ini merupakan pasar potensial yang besar bagi para pelaku bisnis, termasuk untuk UMKM. Menurut (Octavia et al., 2020), ecommerce sendiri adalah proses jual beli barang atau jasa secara elektronik yang terkomputerisasi. UMKM perlu didorong untuk menggunakan e-commerce agar tidak ketinggalan dengan bisnis yang telah mengadopsi e-commerce (Religia et al., 2021). Berdasarkan penelitian (Octavia et al., 2020), bahwa adopsi e-commerce memiliki pengaruh yang signifikan dalam peningkatan kinerja bisnis UMKM. Penjualan ritel melalui e-commerce di Indonesia sendiri sangat besar, bahkan lebih besar dibandingkan dengan penjualan e-commerce di negera-ngeara di ASEAN (Religia et al., 
2021). Namun, penggunaan e-commerce untuk penjualan, belum sepenuhnya dapat diimplementasikan dengan baik oleh para UMKM. Dengan begitu, karya tulis ini ingin mengidentifikasi faktor-faktor apa saja yang menpengaruhi adopsi e-commerce bagi UMKM, dengan melihat penerapan e-commerce yang sulit dan juga pentingnya bagi UMKM. Karya tulis ini disusun sebagai berikut, bagian pertama menjelaskan pendahuluan dan tujuan karya tulis ini; bagian kedua menjelaskan faktor yang mempengaruhi adopsi e-commerce; bagian ketiga menyajikan metode yang digunakan; dan bagian terakhir membahas kesimpulan. Kesimpulan karya tulis ini diharapkan dapat membantu UMKM untuk tumbuh dan juga dapat menyediakan informasi dan pengetahuan yang dibutuhkan untuk pengembilan keputusan.

\section{Tinjauan Pustaka}

\section{E-commerce}

E-commerce adalah dimana dapat membeli dan menjual produk dan layanan melalui internet dan penggunaan sistem computer untuk meningkatkan efisiensi perusahaan (Alzahrani, 2019). Selain itu, e-commerce didefinisikan sebagai kegiatan ekonomi melalui internet termasuk menjual atau membeli produk dan jasa (Rosnita, 2019). Kegiatan ekonomi ini terjadi baik sebagai business-tobusiness (B2B), business-to-consumer (B2C), customer-to-customer (C2C), atau customer-tobusiness $(C 2 B)$. E-commerce tidak hanya sebagai saluran untuk melakukan bisnis, tetapi juga sebagai aplikasi solusi teknologi informasi untuk membantu mendifinisikan dan mengembangkan strategi baru untuk mengatasi masalah bisnis. Bisnis dapat terbantu dari keutungan e-commerce itu sendiri. Manfaat e-commerce bagi UMKM salah satunya adalah memperoleh manfaat dari ketersediaan layanan 24 jam, mengjangkau pelanggan dengan luas, meningkatkan hubungan dengan pelanggan dengan baik, pertukaran informasi, memenuhi kebutuhan pelanggan, efektivitas biaya (Alzahrani, 2019), serta meningkatkan penjualan dan produktivitas (Awa et al., 2015). (Alzahrani, 2019) juga menemukan bahwa mengadopsi e-commerce adalah penting untuk mencapai keunggulan kompetitif dan strategis, terutama untuk usaha kecil. Berdasarkan $C N B N$ Indonesia (2021), bahwa jumlah presentase pengguna e-commerce di Indonesia adalah tertinggi, yaitu sebesar $88,1 \%$. Melihat ini, tepat bagi UMKM untuk mengadopsi e-commerce agar mampu bersaing dan unggul.

\section{Usaha Mikro Kecil Menengah (UMKM)}

UMKM atau Usaha Mikro Kecil Menengah adalah perusahaan independent yang mempekerjakan sedikit karyawan (Alzahrani, 2019). Di Indonesia, UMKM didefinisikan sebagai usaha dengan penjualan tahunan paling banyak Rp300 juta atau kekayaan bersih (tidak termasuk tanah dan bagunan) kurang dari Rp50 juta (Rosnita, 2019). Terminologi UMKM sering digunakan oleh negara maju. UMKM sendiri memainkan peran penting dalam perekonomian sebagian besar negara (Awa et al., 2015). Adopsi e-commerce telah berdampak pada UMKM secara global dalam 
pertumbuhan penjualan, efisiensi biaya, peningkatan proses layanan, dan kualitas produk (Rosnita, 2019). Untuk mengadopsi e-commerce, perlu menerapakan pendekatan strategis.

\section{Faktor-faktor yang Mempengaruhi UMKM untuk Mengadopsi E-commerce}

\section{Teknologi}

Variabel teknologi dikaitan dengan tiga indikator, antara lain keuntungan relatif, kompelistas yang dirasakan, dan kompabilitas. Keunggulan relatif adalah keadaan sejauh mana adopsi inovasi dianggap mampu memberikan manfaat yang lebih besar bagi perusahaan daripada mempertahankan inovasi sebelumnya (Alsaad et al., 2017; Religia et al., 2021). Lalu, indikator kompleksitas adalah indikator yang mengacu pada kondisi di mana adopsi inovasi dianggap relatif sulit atau tidak saat digunakan. Dan indikator lainnya adalah, indikator kompatibilitas yang mengacu pada tingkat kesiapan pengguna terhadap infrastruktur teknologi yang ada, dan praktik kerja yang diinginkan perusahaan (Religia et al., 2021).

\section{Perusahaan}

Variabel perusahaan dikaitan dengan indikator, antara lain dukungan manajemen, pengetahuan teknologi informasi, serta ukuran perusahaan (Gono et al., 2016; Religia et al., 2021). Dukungan manajemen ini mengacu pada sejauh mana pemimpin perusahaan memahami e-commerce. Lalu, indikator selanjutnya adalah pengetahuan teknologi informasi dimana pengetahuan akan teknologi yang dimiliki karyawan sangatlah penting. Dari sini akan dilihat apakah perusahaan mampu mengadopsi e-commerce atau tidak, dan begitu juga dengan ukuran perusahaan.

\section{Lingkungan}

Variabel lingkungan ini dikaitkan dengan dua indikator, yakni tekanan dari pesaing dan tekanan dari mitra dagang. Ketika para pesaing telah mengadopsi e-commerce, perusahaan pasti akan terdorong untuk ikut mengadopsi agar tetap unggul dan tidak kalah saing. Sedangkan, tekanan dari mitra dagang, seperti pemasok dan pelanggan pun dapat mempengaruhi untuk mengadopsi e-commerce (Religia et al., 2021).

\section{Metodologi}

Karya tulis ini ditulis dengan menggunakan metode tinjauan pustaka atau literature review, dimana penulis mencari dan mempelajari jurnal-jurnal, baik internasional maupun nasional yang didapatkan dari berbagai sumber melalui internet. Jurnal-jurnal tersebut dipelajari untuk menghasilkan sebuah kesimpulan dari tujuan karya tulis ini.

\section{Kesimpulan}


Penggunaan e-commerce yang pesat telah mendorong UMKM untuk mengadopsi e-commerce. Adopsi e-commerce memungkinkan dapat memberikan keunggulan kompetitif bagi UMKM di era ekonomi yang sudah berbasis teknologi. Namun, tidak semua UMKM dapat mengadopsi ecommerce dengan mudah. Padahal, UMKM sendiri merupakan salah satu bagian penting dari perekonomian di banyak negara. Dengan begitu, berdasarkan kesimpulan yang didapat dari beberapa jurnal adalah bahwa adopsi e-commerce didorong oleh faktor teknologi, perusahaan, dan lingkungan itu sendiri.

\section{Referensi}

Alsaad, A., Mohamad, R., \& Ismail, N. A. (2017). The Moderating Role of Trust in Business to Business Electronic Commerce (B2B EC) Adoption. Computers in Human Behavior, 68, 157-169. https://doi.org/10.1016/j.chb.2016.11.040

Alzahrani, J. (2019). The Impact of E-commerce Adoption on Business Strategy in Saudi Arabian Small and Medium Enterprises (SMEs). Review of Economics and Political Science, 4(1), 73-88. https://doi.org/10.1108/reps-10-2018-013

Awa, H. O., Baridam, D. M., \& Nwibere, B. M. (2015). Demographic determinants of electronic commerce (EC) adoption by SMEs: A twist by location factors. Journal of Enterprise Information Management, 28(3), 326-345. https://doi.org/10.1108/JEIM-10-2013-0073

Gono, S., Harindranath, G., \& Berna Özcan, G. (2016). The Adoption and Impact of ICT in South African SMEs. Strategic Change, 25(6), 717-734. https://doi.org/10.1002/jsc.2103

Octavia, A., Indrawijaya, S., Sriayudha, Y., Heriberta, Hasbullah, H., \& Asrini. (2020). Impact on E-commerce Adoption on Entrepreneurial Orientation and Market Orientation in Business Performance of SMEs. Asian Economic and Financial Review, 10(5), 516-525. https://doi.org/10.18488/journal.aefr.2020.105.516.525

Ramdansyah, A. D., \& Taufik, H. E. R. (2017). Adoption Model of E-Commerce from SMEs Perspective in Developing Country Evidence-Case Study for Indonesia. In European Research Studies Journal: Vol. XX.

Religia, Y., Surachma, Rohman, F., \& Indrawati, N. K. (2021). E-Commerce Adoption in SMEs: A Literature Review.

Rosnita, W. (2019). The Impact of E-commerce Adoption on MSMEs Performance and Financial Inclusion (FI) in Indonesia.

Saroso, H., Hida Syahchari, D., Sudrajat, D., \& Grace Herlina, M. (2019). E-Service Quality and Corporate Image on Customer Perception. In International Journal of Innovation, Creativity and Change. www.ijicc.net (Vol. 10, Issue 8). www.ijicc.net 